\title{
Research on the Technology Innovation with SEM model Based on Data Mode Analysis
}

\author{
Xiaoqing $\mathrm{Bi}^{1, \mathrm{a},}$ Xue $\mathrm{Li}^{2, \mathrm{~b}}$ \\ ${ }^{1}$ School of Management, Tianjin University of Technology, Tianjin, China \\ ${ }^{2}$ School of Management, Tianjin University of Technology, Tianjin, China \\ abi_xiaoqing@163.com, 'liyuanmuzi@163.com
}

Keywords: Technology innovative, SEM model, Data mode analysis, SPSS software.

\begin{abstract}
The current study shows that the impact of technology innovative of enterprises become more important. In order to promote the development of enterprises and improve the economic performance, in this paper, we study the problem is: for the different goal orientation of staff performance, performance appraisal will produce what kind of impact on their technology innovative behavior. Through empirical research with SEM model and SPSS software, we found that the performance appraisal does have different effects on innovative behavior of individual goal orientation.
\end{abstract}

\section{Introduction}

Enterprise development is increasingly dependent on technology innovation. Individual innovation is the basis of the team and organization innovation[1]. Studies have shown that the intrinsic characteristics of individual and organizational contexts are two important variables affecting individual innovation[2]. Individual goal orientation has important influence on innovation behavior[3], and the performance appraisal is situational factors affecting the behavior of the individual.

\section{Review of the Literature and hypotheses}

Concept definition. 1) Employee Innovative Behavior. Most management experts define individual innovation from the point of a process view. Amabile (1988) considered the individual innovation behavior refers to a person to produce novel, appropriate ideas at work and find solutions to the problem. It is a process of performance[4].

2) The Goal Orientation of Employees. Individual goal orientation refers to the pursuit of goal in a work[5], it considering individual behavior is decided by its willingness to achieve a certain goal, therefore in the context of accomplishments, goal orientation determines the respond to the event and result. This research adopts the Vande Walle's theory[6], namely learning goal orientation, proving goal orientation and avoiding orientation, exploring their relationship with the employee innovation. Learning goal orientation individual is to learn new skills to improve their ability. Proving goal orientation individual prove their ability in order to get a positive evaluation of others. Avoiding goal orientation individual does not want to be proven inability so escape negative capability evaluation.

3) Goal Orientation in Performance Appraisal. Goal-oriented performance appraisal refers to the final purpose of employee perceived organizational performance assessment tools. With further study, scholars divided into the evaluation performance appraisal and development performance appraisal based on two purposes.

Hypotheses proposed. i) The relationship between individual goal orientation and Employee Innovative Behavior. The individual goal orientation is an important intrinsic motivation variables, thus showing the different patterns of behavior[7]. Xing Chunhui, Shi Jintao verified that the learning goal orientation is the key factor of individual innovation behavior, that proving goal-oriented has a positive relation with innovative behavior, that avoiding goal orientation had no 
significant influence on innovative ideas, but has a negative effect on innovative ideas to implement[8].

H1a: There is a positive relation between learning goal orientation and innovative behavior.

$\mathrm{H} 1 \mathrm{~b}$ : There is no significant relation between proving goal-oriented and innovation behavior.

H1c: There is a negative relation between avoiding goal-oriented and innovation behavior.

ii) The relationship between goal-oriented performance appraisal and innovation behavior

Some scholars think that evaluation oriented performance assessment is mandatory and repressive, will make staff complete performance indicators for instant success. The domestic scholar Yin Runfeng demonstrated that the development performance evaluation has a promoting effect on innovation behavior [9]. Therefore, forward the following hypothesis:

$\mathrm{H} 2 \mathrm{a}$ : There is a negative relation between evaluation performance and innovation behavior.

$\mathrm{H} 2 \mathrm{~b}$ : There is a positive relation between development performance and innovation behavior.

iii) evaluation oriented performance assessment plays a moderating role on innovation behavior

Evaluation oriented performance assessment will exert some control on the staff, in this control, the staff's attention will shift from working hard to cope with assessment, which lack the inherent motive of innovation[10]. Learning goal orientation will make the staff enhance external motivation. Extrinsic motivation crowd out effect on internal motivation, thus reducing the motivation of innovation. The fundamental objective of evaluation oriented performance is the assessment of punishment, avoiding oriented individuals would be more reluctant to change the status quo in order to prevent the risk of failure. It is not conductive to innovation behavior. In order to prove their abilities to others, the proving oriented individuals show some innovation behavior finally. However, the evaluation-oriented performance appraisal emphasize that job performance, proving oriented individual would not want to spend too much energy for innovation activities because of the risk and poor performance. Therefore, this paper put forward the following hypothesis:

$\mathrm{H} 3 \mathrm{a}$ : The evaluation oriented performance appraisal weaken the positive relationships between learning goal orientation and employee innovative behavior.

$\mathrm{H} 3 \mathrm{~b}$ : The evaluation oriented performance appraisal strengthen negative relationships between avoiding goal orientation and employee innovative behavior.

H3c: There is a uncertain relationship between proving goal orientation and innovation behavior.

Development oriented performance makes employees feel the organization's support and help in order to form a atmosphere of trust, encourage, tolerate failure and free. It will be beneficial employees's innovative behavior. Therefore, this paper put forward the following hypothesis:

H4a: Development oriented performance assessment has a positive moderating effect on the relationship between learning goal orientation and innovative behavior.

H4b: Development oriented performance assessment has a positive moderating effect on the relationship between proving goal orientation and innovation behavior.

H4c: Development oriented performance assessment has a positive moderating effect on the relationship between avoiding goal orientation and innovation behavior.

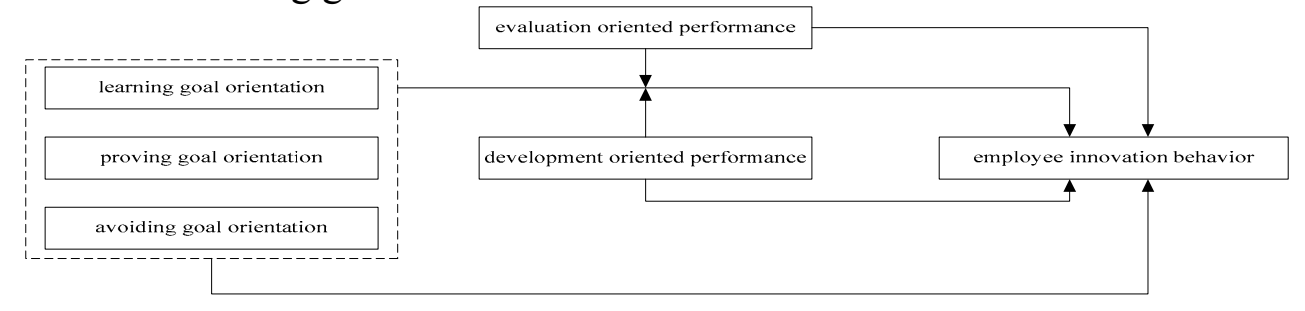

Fig. 1 research mode

\section{Research Methods}

The participants. 457 employees of the study in August 1, 2013 to October 3, 2013 in Beijing, Tianjin high-tech enterprises conducted a questionnaire survey. About 457 questionnaires were distributed, 392 questionnaires were recovered, 377 valid questionnaires were obtained finally. 
Variables measuring. The study use the foreign existing research scale which has been widely used in the literature in order to ensure the reliability and validity of measurement tools. Goal orientation measurement reference Vande Walle (1999) designed specifically for the employees of the scale. Performance appraisal goal orientation scale uses Wen Peng, Liao Jianqiao's scale. Employee innovation adopt Scott and Bruce's scale[11]. In the questionnaire, all scale measurement use Linker five point scale.

\section{Results}

The reliability and validity analysis. This article mainly uses the support SPSS11.5 and Amos27.0 two kinds of statistical package for the questionnaire analysis tool. We obtained reliability and structural validity of questionnaire data throughout SPSS17.0 software. As shown in Table 1. The variable coefficient are all more than 0.8 , show that the questionnaire has good validity.( Individual goal orientation, $\mathrm{a}=0.868$ Learning goal orientation, $\mathrm{a}=0.961$ Proving goal orientation, $\mathrm{a}=0.864$ Avoiding goal orientation, $\mathrm{a}=0.779$ Goal Orientation in Performance Appraisal , $\mathrm{a}=0.867$ Development oriented performance , $\mathrm{a}=0.847$ Evaluation oriented performance , $\mathrm{a}=0.888$ Employee Innovative Behavior, $\mathrm{a}=0.810$ )

In terms of validity check, confirmatory factor analysis results are as follows: See table 1

\begin{tabular}{|l|l|l|l|l|l|l|l|}
\hline & Table 1:Fitting analysis & & & & & \\
\hline Fitting index & $\chi 2 / \mathrm{df}$ & GFI & NFI & IFI & CFI & RMR & RMSEA \\
\hline $\begin{array}{l}\text { Three-factor structure of individual } \\
\text { goal orientation }\end{array}$ & 3.21 & 0.92 & 0.92 & 0.94 & 0.95 & 0.04 & 0.07 \\
\hline $\begin{array}{l}\text { Employee Innovative } \\
\text { Behavior of a factor structure }\end{array}$ & 3.41 & 0.91 & 0.91 & 0.95 & 0.96 & 0.05 & 0.07 \\
\hline $\begin{array}{l}\text { Performance appraisal goal-oriented } \\
\text { two-factor structure }\end{array}$ & 3.33 & 0.93 & 0.96 & 0.97 & 0.97 & 0.03 & 0.06 \\
\hline
\end{tabular}

Data Analysis and Results. i) The variable correlation analysis. The following table gives the correlation coefficient between the variables in this paper $(\mathrm{IB}=$ employee innovative behavior, $\mathrm{DA}=$ development oriented performance, $\mathrm{EA}=$ evaluation oriented performance, $\mathrm{GL}=$ learning goal orientation, $\mathrm{GP}=$ proving goal orientation, $\mathrm{GA}=$ avoiding goal orientation). From the table we can see learning goal orientation and employee innovative behavior are positively related, avoiding goal orientation and employee innovative behavior are negatively correlated, proving goal orientation and employee innovative behavior are of weak correlation. In addition, the evaluation oriented performance and employee innovative behavior are negatively correlated, the development oriented performance and employee innovative behavior are positively related.

Table 2 The variable coefficient of internal consistency and correlation analysis

\begin{tabular}{|c|l|l|l|l|l|l|}
\hline & DA & EA & GL & GP & GA & IB \\
\hline DA & 1 & & & & & \\
\hline EA & $-0.649^{* *}$ & 1 & & & & \\
\hline GL & $0.426^{* *}$ & $-0.549^{* *}$ & 1 & & & \\
\hline GP & $0.590^{* *}$ & $-0.576^{* *}$ & $0.560^{* *}$ & 1 & & \\
\hline GA & $-0.740^{* *}$ & $0.895^{* *}$ & $-0.412^{* *}$ & $-0.677^{* *}$ & 1 & \\
\hline IB & $0.690^{* *}$ & $-0.688^{* *}$ & $0.652^{* *}$ & $0.147^{* *}$ & $-0.604^{* *}$ & 1 \\
\hline
\end{tabular}

ii) The relationship between goal orientation performance and Employee Innovative Behavior. Using multivariate regression analysis test the relationship between the variables in the basis of correlation inspection. From the result, under the effect of control variables, the learning goal orientation have significant positive influence on employees getting validation $(\beta=0.616, p<0.001)$; that goal orientation of individual significance level is higher than $0.05 \quad(\beta=0.089, p>0.05)$; Avoiding goal orientation has a significant negative effect on employee innovative behavior verified $(\beta=-0.568, \mathrm{p}<0.001)$. Evaluation-oriented performance appraisal has a significant negative impact on employee innovative behavior $(\beta=-0.399, \mathrm{p}<0.001)$, and the development-oriented 
performance appraisal has significantly positive impact on employees innovative behavior $(\beta=$ $0.404, \mathrm{p}<0.001)$.

Make goal orientation of employees through the performance evaluation and individual innovation behavior by regression analysis, get the table 4 . Through the B2 we can see that the evaluation performance appraisal on learning goal orientation and innovative behavior have significant negative regulation $(\beta=-0.473, \mathrm{P}<0.001)$, evaluation-oriented performance appraisal impaired the relationship between learning goal orientation and innovation behavior; model $\mathrm{C} 2$ shows that the evaluation performance has certain influence on the relationship between proving goal orientation and innovative behavior $(\beta=-0.334, \mathrm{P}<0.05)$, Model D2 shows the evaluation model of performance appraisal has certain effect on regulating the relationship between the avoidance goal orientation and innovative behavior $(\beta=0.267, \mathrm{P}<0.01)$.

Model B1, C1, D1 shows the moderating effect of developmental performance appraisal on individual goal orientation dimensions and employee innovative behavior in the table 4. After joining the development of performance appraisal, development performance positively moderates the relationship between learning goal orientation and innovative behavior $(\beta=0.254, \mathrm{P}<0.001)$, model $\mathrm{C} 1$ shows development performance positively moderates the relationship between proving goal orientation and innovative behavior $(\beta=0.251, \mathrm{p}<0.05)$, model D1 shows development performance negatively moderates the relationship between avoiding goal orientation and innovative behavior $(\beta=-0.211, \mathrm{p}<0.01)$.

Table 4 Performance appraisal goal orientation and goal-oriented interaction of individual

innovation behavior regression

\begin{tabular}{|c|c|c|c|c|c|c|}
\hline & \multicolumn{6}{|c|}{ The dependent variable innovative behavior } \\
\hline $\begin{array}{l}\text { Control } \\
\text { variables }\end{array}$ & Model B1 & Model C1 & Model D1 & Model B2 & Model C2 & Model D2 \\
\hline GL & $0.280^{* *}$ & & & $0.292 * *$ & & \\
\hline GP & & $0.329 *$ & & & 0.044 & \\
\hline GA & & & -0.251 & & & -0.104 \\
\hline DA & $0.588 * * *$ & $0.568 * * *$ & $0.556 * * *$ & & & \\
\hline $\mathrm{DA} * \mathrm{GL}$ & $0.254 * * *$ & & & & & \\
\hline $\mathrm{DA} * \mathrm{GP}$ & & $0.251^{*}$ & & & & \\
\hline $\mathrm{DA}^{*} \mathrm{GA}$ & & & $-0.211 * *$ & & & \\
\hline EA & & & & $-0.492 * *$ & $-0.349 * *$ & $-0.430 * *$ \\
\hline $\mathrm{EA}^{*} \mathrm{GL}$ & & & & $-0.473 * *$ & & \\
\hline $\mathrm{EA}^{*} \mathrm{GP}$ & & & & & $-0.334 *$ & \\
\hline EA*GA & & & & & & $0.267 * *$ \\
\hline $\mathrm{F}$ & $27.581 * *$ & $27.582 * *$ & $28.052 * * *$ & $20.679 * *$ & $20.619 * *$ & $20.603 * * *$ \\
\hline $\begin{array}{l}\text { Adjust the } \mathrm{R} \\
\text { square }\end{array}$ & 0.653 & 0.653 & 0.657 & 0.583 & 0.585 & 0.597 \\
\hline
\end{tabular}

\section{Conclusion}

The empirical results show that the individual goal orientation plays a very important role on innovative behavior. Learning goal orientation has significantly positive impact on innovative behavior, avoiding goal orientation has a significant negative effect on innovative behavior, proving goal-oriented individuals did not significantly impact on employees innovative behavior, this shows that goal orientation whether or not show the innovation behavior depends on the change of external environment. Through analyzing the research hypothesis testing found that development oriented performance have a positive regulates on employee innovative behavior with goal orientation, Evaluation Oriented Performance Appraisal weakened the positive relationship between learning goal orientation and employee innovative behavior, and strengthen the negative relationship between avoiding goal orientation and employee innovative behavior, which shows that in terms of motivating employees, evaluation-oriented performance appraisal plays some negative effects. 


\section{References}

[1] King, N. Modeling the Innovation Process: An Empirical Comparison of Approaches. Journal of Occupational and Organizational Psychology, 1992, 65: 89-100.

[2] J. Zhang. Study on the influence of organizational contexts staff's creative performance and motivation mechanism. Capital Normal University,2003

[3] H. Meng and J. Ni, (2002). Review of the Relationship among goal orientation, feedback seeking and performance. Psychological Science, 25 (4) :457-460

[4] Amabile, T. M. A model of creativity and innovation in organizations. Research in Organizational Behavior.1988(10):123-167

[5] F.Z., Xu Z.X. Zhu. The relationship between Target inclination measurement and performance. Journal of psychological development and education.2000 (2) : 1-6

[6] VandeWalle, D. Cron, W. L\&Slocum, J.W., Jr. (2001). The role of goal orientation following performance feedback. Journal of Applied Psychology,86: 629-640

[7] Dweck, C.S.Motivational Processes Affecting Learning.American Psychologist, 1986,41:1040-1048.

[8] C.H. Xing and J.T Shi.. Effect of Goal Orientation on Individual Innovation Work Behavior. Journal of Wuhan University of Technology(Information \& Management Engineering), 2009,4(31):673-680.

[9] R.F. Yin, Influence of Goal Orientation in Performance Appraisal on Staff Innovative Behavior-Mediating Effect of Staff Error Learning. Journal of Industrial Technological Economics, $2011,217(11): 12-16$

[10] Shalley C.E., Zhou J, Oldham G R. The Effect of Personal and Contextual Characteristics on Creativity: Where Should We Go from Here.Journal of Management,2004,30,(6):933-958.

[11] Scott S G, Bruce R A. Determinants of innovative behavior: A path model of individual innovation in the work place. Academy of Management Journal, 1994, 37(3):580-607 